\title{
A ludicidade no "jogo" de relações trabalho/escola
}

\author{
José Ângelo Gariglio*
}

O objetivo deste texto é, inicialmente, tentar discutir as relações de subserviência e clientelismo nos quais a escola se insere frente ao mundo do trabalho alienado, legitimando as práticas sociais que fundamentam os parâmetros básicos da ideologia capitalista.

Ele procura, também, avançar esta discussão, tentando analisar a instituição escolar como um espaço dialético, onde podem existir perspectivas de mecanismos de resistência frente ao "jogo" imposto pela lógica do trabalho capitalista. Esta possibilidade de movimentos antagônicos dentro do universo escolar se materializa quando se discute a possibilidade de existência do lúdico em seu interior, abrindo espaço para uma reflexão acerca da dimensão revolucionária do jogo lúdico e tentando colocar, frente a frente, as características fundamentais da "lógica" lúdica e da lógica do trabalho.

O texto invade, ainda, o universo da Educação Física, com reflexões sobre suas características específicas que potencialmente e naturalmente poderiam estar mais próximas da vivência lúdica. Entretanto, apesar destas características próprias da Educação Física, a ela, como todas as outras disciplinas escolares, são delegadas funções e objetivos por uma ordem institucional que impedem e bloqueiam a manifestação de uma ordem própria e de manifestações autônomas. A Educação Física estaria, portanto, comprometida na manutenção da ordem escolar e ao mesmo tempo ajudando a formar indivíduos reprodutores e mantedores da ordem social.
Este trabalho tenta, enfim, apontar perspectivas de mudanças dentro deste complexo jogo de relações, perspectivas que passariam pela rediscussão do que é e do que pode ser uma instituição e também abraçar uma educação para e pelo lazer.

\section{TRABALHO X AÇÃO}

\section{PEDAGÓGICA - INCORPORANDO} A LÓGICA DO MUNDO PRODUTIVO

Com o advento da Revolução Industrial as relações de produção se modificariam, sendo a nova tônica caracterizada pelos princípios do modelo de produção capitalista. Nessa lógica os trabalhadores, cada vez mais tendem a perder o controle sobre as formas de produção, sobre o que produzir, onde produzir e muitas vezes são privados do consumo do que produziriam. Para Fernandez (1989) a sociedade industrializada nestes princípios retirou dos trabalhadores todo o controle sobre o processo de produção, sobre a sua intensidade e seu tempo, dicotomizando a produção do consumo e do ócio.

Perante esta nova ordem sócio-produtiva, tornou-se imperativo organizar as instituições com o objetivo de se adaptar toda essa massa trabalhadora, que antes da Revolução Industrial vivia numa economia de subsistência, para uma nova realidade que se legitimava pela lógica de produção capitalista.

Assim como outras instituições, a escola se coloca e se legitima como um dos
Este trabalho tenta, enfim, apontar perspectivas de mudanças dentro deste complexo jogo de relações, perspectivas que passariam pela rediscussão do que é e do que pode ser uma instituição e também abraçar uma educação para e pelo lazer. 
veiculadores deste novo projeto de sociedade. Fernandez (1989) destaca que a instituição e o processo escolar estão organizados de forma tal que as salas de aula se converteram no lugar apropriado para acostumar-se às relações sociais de processo de produção capitalista, num espaço institucional adequado para preparar as crianças e os jovens para o trabalho.

A Escola surge, neste contexto, como uma das instituições que reproduz, sob múltiplas formas, as práticas sociais do universo produtivo e a divisão do trabalho imperante na sociedade, fragmentando o trabalho manual do intelectual e dando, a cada um destes, papéis diferentes. Como afirma Fernandez (1989), a escola acaba por determinar ao primeiro a execução e ao segundo a concepção.

A este "jogo" de relações entre escola e trabalho o autor denomina de Teoria da Correspondência". Este "jogo" tenta produzir, na nossa sociedade, um certo ar de funcionalidade através do qual cada indivíduo tenha seu papel e função, sem que haja conflitos e discussões. Para este autor a escola entra nesse "jogo" com o propósito de produzir os modos de comportamento e as atitudes necessárias para uma convivência não conflitiva no mundo do trabalho. Portanto, a correspondência entre estes dois universos instrumentaliza-se no cotidiano escolar de vária formas.

Primeiramente, esta realidade se evidência através de uma educação que faz os alunos conviverem submissamente com a disciplinarização. Neste sentido, Fernandez (1989) destaca que a escola assume a educação socializadora para a ordem, a autoridade, a submissão e a disciplina.

A outra similaridade entre trabalho e escola coloca-nos diante da necessidade de uma educação que prepare os indivíduos para a aceitação de um estado de alienação perante o processo produtivo. Marx caracterizou o trabalho na sociedade capitalista, em comparação ao trabalho em geral, como trabalho alienado e apontou que esta alienação residia, basicamente, na relação entre o trabalhador e o produto, o processo e os meios de seu trabalho.

Pensando a escola a partir desta constatação percebemos que existem mecanismos utilizados para adaptarem os alunos a esta realidade da lógica do trabalho alienado. Assim como Marx denuncia a alienação do trabalhador perante o processo produtivo, Fernandez alerta para a correspondência de objetivos entre escola e trabalho quando revela, como uma das funções da escola, a produção de uma educação que coloque o aluno em um estado de alienação frente o processo de ensino. Para este autor, o aluno escolarizado carece da capacidade de decidir o que aprender e como aprender. Assim sendo, a escola prepara os indivíduos para aceitação de atividades desinteressantes e desvinculadas de motivações intrínsecas, nas quais as "recompensas"se encontram fora e longe da vivência do processo de aprendizagem.

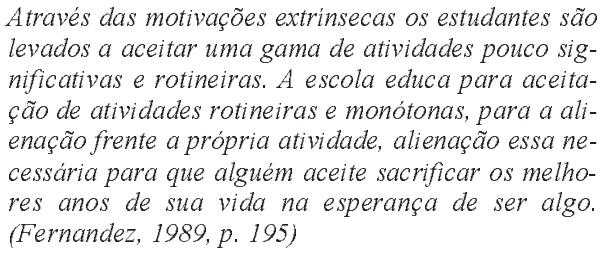

Através das motivações extrinsecas os estudantes são levados a aceitar uma gama de atividades pouco significativas e rotineiras. A escola educa para aceitacão de atividades rotineiras e monótonas, para a alienação frente a própria atividade, alienação essa necessária para que alguém aceite sacrificar os melhores anos de sua vida na esperança de ser algo. (Fernandez, 1989, p. 195)

Paralelamente à educação que leva o aluno a um estado contemplativo em relação ao processo de ensino, observamos, também, no cotidiano escolar, mecanismos que veiculam, com muita eficácia, um dos pilares de sustentação do sistema produtivo capitalista na nossa sociedade. Refiro-me ao estímulo à competição interindividual. Esta educação é estimulada dentro da escola principalmente pela valorização de recompensas extrínsecas tais como: notas, provas, freqüência, aceitação da imagem e cumprimento de horário. Este estímulo competitivo tem como conseqüência nefasta a dispersão dos grupos sociais ainda dentro do universo escolar. Diante disso Fernandez afirma que a escola empenha-se em romper com os vínculos grupais entre os alunos, socializando-os sistematicamente no individualismo, na competição e na falta de solidariedade, preparando o terreno para que amanhã torne-se difícil erigir outro gênero de relações entre eles e, em particular, para que não sejam capazes de agir de forma solidária frente a seus empregadores.

Entretanto, após termos tentado identificar quais os tipos de relações e os objetivos que levam a escola a reproduzir as práticas sociais do mundo do trabalho capitalista e, também, constatarmos que tais práticas se 
apresentam hegemonicamente na nossa sociedade, acreditamos na existência de movimentos antagônicos e de resistência dentro da instituição escolar, dentre os quais citamos: a possibilidade de vivência lúdica. Movimentos dessa natureza são produzidos pela própria estrutura, que mesmo que tente esta, paradoxalmente, de toda forma impor a lógica dominante, colocando-a como uma verdade única, tentando de todas as formas sufocar reações autônomas de vontades individuais e coletivas.

Assim sendo, precisamos atentar para a existência dos desejos ocultos, de uma ordem cultural reprimida e marginalizada, abrindo possibilidades para a expressão. Apesar de serem reprimidos em prol de uma concepção de verdade que fundamenta a lógica dominante, podem revelar, potencialmente, uma alternativa de mudança e de contradição.

Se a percepção e a compreensão dos desejos e da cultura produzida por grupos sociais específicos tornam-se importantes para a construção de um projeto revolucionário, vem à tona a necessidade de se discutir o lúdico como um dos espaços de vivência desejada e construtora de cultura e que, por isso, pode se tornar um foco de resistência frente ao "jogo" de correspondências entre a lógica do trabalho e a lógica da escola.

\section{JOGO LÚDICO: ESPAÇO \\ DE RESISTÊNCIA NA ESCOLA?}

Aberta a perspectiva de contradição dentro da escola, quero falar do jogo como alternativa de resistência frente à lógica racionalista do trabalho legitimado nesta.

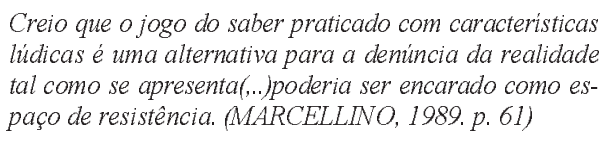

Contudo, seria possível a existência do jogo lúdico na escola? E como o jogo lúdico poderia se constituir em um dos mecanismos de resistência no meio escolar? Para caminharmos nesta reflexão, ampliando a discussão sobre este assunto, procuraremos identificar as características básicas da "lógica" lúdica.

Huizinga, em Homo Ludens, delimita o universo lúdico em alguns pontos básicos, considerando a maneira pelas quais suas características principais se manifestam. Para esse autor, a vivência lúdica leva o participante: a) à experiência da liberdade e da gratuidade; b) à construção de uma vivência num espaço e tempo próprio exterior a vida real; c) ao envolvimento total e intenso nesta atividade: d) à prática da construção da ordem e regras próprias; e) à oportunidade para a formação e convivência com grupos sociais.

Porém, a visão do referido autor coloca a ludicidade como um universo desvinculado e descontextualizado da realidade concreta exterior a ele, apesar de afirmar que o jogo é base da cultura. Nessa perspectiva, o jogo perderia o seu caráter crítico e revolucionário.

Para fazer o contraponto a esta perspectiva lúdica, Marcellino (1990) resgata o papel revolucionário do jogo quando o encara de forma dialética, afirmando conceber o jogo como um espaço privilegiado de cultura, onde há a possibilidade de criar e usufruir da mesma, permitindo a vivência de valores externos a ele de forma crítica e criativa e representando, assim, uma denúncia da realidade exterior, ao mesmo tempo que a alimenta e dela se alimenta.

Diante do exposto, buscamos relativizar o jogo como um espaço de contradição frente a lógica do mundo do trabalho, reproduzida e legitimada no cotidiano escolar. Então vejamos:

A) Enquanto a escola, em geral, se caracteriza pela formação para a disciplina e submissão, poderia o jogo do saber, com características lúdicas, possibilitar uma abertura para a construção coletiva das regras e de uma ordem própria?

B) Enquanto a escola, na maioria das vezes, faz com que os alunos se coloquem de maneira alienante frente ao conteúdo de ensino e o processo de aprendizagem, o jogo do saber com características lúdicas conseguiria absorver os alunos de forma total e intensa nas atividades propostas pelo professor?

C) Enquanto a escola, quase sempre educa para a aceitação da chateação, da monotonia, da dissociação interna da própria
Se a percepção e a compreensão dos desejos e da cultura produzida por grupos sociais especificos tornam-se importantes para a construção de um projeto revolucionário, vem à tona a necessidade de se discutir o lúdico como um dos espaços de vivência desejada e construtora de cultura 
atividade, o jogo poderia acontecer na escola, proporcionando aos alunos situações prazerosas, envolventes, emocionantes e plenas?

D) Enquanto na escola a determina ção do tempo e espaço das atividades perten ce hegemonicamente à instituição, o jogo, ca racterizado por limites espaciais e temporais próprios, poderia se manifestar, mesmo que a situação concreta dos alunos impeça isto?

E) Enquanto na escola é estimulada a dispersão dos grupos sociais e, conseqüente mente, o individualismo por intermédio da competição, o jogo, que se caracteriza por ser socializante e gregário, poderia se manifestar produzindo uma vivência de coletividade neste cotidiano?

F) Enquanto na escola a motivação é embasada, geralmente, por recompensas extrínsecas (interesse material), o jogo do sa ber com características lúdicas poderia se rea lizar, possibilitando aos indivíduos inseridos no contexto escolar uma vivência gratuita com recompensas intrínsecas?

G) Enquanto na escola legitima-se a competição, valorizando o produto em detri mento do processo, como o jogo poderia con trariar esta lógica, valorizando tanto o proces so como o produto?

Defender a possibilidade da manifestação lúdica na escola não significa, entretanto, concordar com a idéia de sua institucionalização na mesma. Como defende Marcellino (1989) "o lúdico não tem 'utilidade social', nem é 'produtivo' e, portanto, a tentativa de institucionalizá-lo fatalmente causaria sua morte".

O que nos parece importante é tentar buscar, no cotidiano escolar, mecanismos de abertura para que o lúdico se manifeste, de maneira que sua existência enfrente as ordens e interesses do poder exterior ou do aparato ideológico que lhe são impostos. É importante sermos sensíveis aos desejos daqueles que, coletiva ou individualmente, vêm tentando construir a existência de possibilidades da vivência lúdica abrindo-nos, dessa fôrma, para a conquista impossivel de um mundo aberto à liberdade e alegria. (Alves, 1986)
Nesta perspectiva o lúdico na escola poderia tornar real a construção de um projeto revolucionário, pois daria aos sujeitos envolvidos neste contexto (alunos, professores, funcionários e pais), mesmo que esporádica e momentaneamente, oportunidade de reapropriação e posse de suas vidas, da sua história e de sua cultura. A partir disso, surgiria a possibilidade de crítica e recriação não só da lógica da escola, mas também da lógica imposta à sociedade como um todo, sendo, portanto considerada como a manifestação da utopia e, dialeticamente, como denúncia da realidade insuportável. (Marcellino, 1987)

\section{EDUCAÇÃO FÍSICA - ESPAÇO DE VIVÊNCIA LÚDICA NA ESCOLA}

Ao tentar defender a vivência do componente lúdico como espaço de resistência e contradição à lógica do trabalho alienado, defendo também a Educação Física como um dos componentes responsáveis pela construção da "lógica" lúdica no interior do cotidiano escolar.

Diante disto, acredito na possibilidade da Educação Física, mais do que as outras disciplinas da escola, estar mais próxima da utopia lúdica, na medida em que a sua especificidade caracteriza-se contrariamente à lógica racionalista que a escola legitima. Apesar da Educação física ter quase sempre cumprido o papel de legitimar práticas sociais do mundo do trabalho e estando, portanto, a sua origem dentro do universo escolar vinculada à necessidade da formação de um cidadão de corpo forte e produtivo a serviço da sociedade industrializada, ela não teria também produzido, através de sua identidade, uma lógica contraditória que dialeticamente negava a lógica massacrante da escola?

A identidade específica da Educação Física, oferecendo movimento, tornaria-se antagônica à lógica da escola na medida em que, primeiramente, conseguisse quebrar a imobilidade contemplativa da sala de aula. Através dessa imobilidade, a escola tenta controlar as manifestações corporais e, com isso, as pessoas como todo mundo. Em segundo lugar, os conteúdos da Educação Física estariam mais próximos da atividade lúdica do que da atividade laborai, geralmente executada numa visão funcionalista e utilitarista. $\mathrm{O}$ ter- 
ceiro ponto a se destacar refere-se à forma de ocupação dos espaços que, habitualmente, a escola proporciona, já que esta disciplina requer, para as suas atividades, uma sala de aula que modifica a rotina de ordem, hierarquia e controle verificada, na maioria das vezes, dentro das outras salas de aula. Finalmente, a Educação Física não adota os sistemas de avaliações formalizados pelas outras disciplinas da escola, em geral avaliando apenas pela freqüência e relativizando, com isso, as formas adotadas pela lógica utilitarista da escola.

Entretanto, esta característica tida como contraditória da Educação Física não garante que sua existência na escola seja o espaço ideal e exclusivo para uma vivência lúdica. Este questionamento se faz na medida em que os preceitos básicos para introdução e existência da Educação Física na escola estiveram e estão intimamente condicionados aos parâmetros básicos de uma lógica institucional.

Desta forma, a vivência lúdica dentro do universo da Educação Física esta condicionada às amarras e normas que a instituição the impõe e as quais está sujeita. Como exemplo podemos citar a duração pré-determinada pela escola de 50 minutos para cada aula duas vezes por semana, colocando a Educação Física à mercê de um horário que determina em quais e quantos dias da semana as aulas acontecem. A racionalização destes mecanismos institucionais pode ser um dos principais empecilhos de uma vivência de ludicidade no cotidiano da Educação Física escolar.

No entanto, entendo que o maior empecilho para a vivência lúdica na Educação Física se coloca, principalmente, nos obstáculos que a lógica escolar impõe aos objetivos específicos da Educação Física, determinando o que ela deva promover a fim de manter a funcionalidade do sistema escolar. Bracht (1992) nos alerta que a

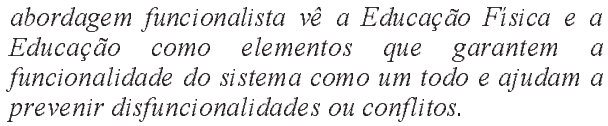

Este caráter funcionalista da Educação Física materializa-se no cotidiano escolar através de uma correspondência muito similar entre os objetivos que permeiam o lazer numa relação a lógica do trabalho e os objetivos da Educação Física em relação à lógica da escola. Isto faz com que a Educação Física incorpore um papel ambíguo. Ela representa o lazer dentro da escola, na medida em que sua função se destina a recuperar o desgaste do aluno dentro da sala de aula para devolvê-lo à mesma reequilibrado e rendendo mais. Ao mesmo tempo que personifica o lazer no universo escolar, ela também educa para assimilação dos valores alienantes da cultura do lazer que compactua com os interesses do processo de produção capitalista, valores estes denunciados por Marcellino (1987) como compensatórios, utilitaristas e moralistas.

Dentro deste contexto, a Educação Física representaria, frente à lógica racionalista da escola, o "oásis" onde todas as frustrações seriam recompensadas, onde todos os desejos reprimidos seriam expostos e onde haveria um espaço para que os alunos pudessem ter um "tempo livre" para realizar o que desejassem, constituindo-se em um ambiente "adequado" para a manifestação lúdica. Diante deste contraponto em que a Educação Física se coloca dentro da escola ela se constitui uma peça fundamental na elaboração do saber escolar. Este saber que dicotomiza trabalho e lazer, que fragmenta o corpo quando divide a teoria da prática, que hierarquiza esta divisão colocando o saber conceituai num plano superior, enfim, constitui-se em um saber escolar comprometido com a manutenção das práticas sociais do mundo do trabalho alienado.

Se a institucionalização do lúdico na Educação Física é usada para manter a ordem escolar, seria possível e verdadeira a manifestação da essência lúdica na mesma? A função principal da Educação Física seria a de proporcionar o lúdico aos alunos como forma de negar a lógica massacrante da escola? Dentro da escola, nos seus espaços sistematizados, o lúdico se manifestaria somente na Educação Física? Como a Educação Física poderia proporcionar a vivência lúdica sem abdicar de transmitir o seu conhecimento? Como a Educação Física e a Educação poderiam reverter esta lógica de dominação? A função compensatória, imposta pela lógica escolar, coloca-se de forma oposta frente ao compensatório esperado pelos alunos? A Educação Física como espaço sistematizado e compartimentalizado para manifestação lúdica na escola não esta- 
ria perpetuando a lógica escolar e reproduzindo a lógica do lazer funcionalista e alienante?

Estas perguntas são fruto de uma reflexão que tenta construir uma Educação Física que possibilite aos alunos, através de sua lógica específica, a vivência lúdica como expressão real de um projeto utópico comprometido com a construção de uma nova escola, de uma nova referência nas relações humanas e enfim, de um ser humano recriador de mundos. Uma Educação Física desarticuladora do saber escolar institucionalizado pelo mundo da produção e que, a partir dela, possa construir com os sujeitos concretos inseridos no universo escolar uma nova referência de valores, que não sejam apenas aqueles referendados pelo mundo do trabalho, mas também pelo mundo do lazer, Enfim, uma Educação

lógica de trabalho

e uma nova lógica

de relação huma-

poderia contribuir

para e pelo lazer. Física que consiga contribuir para a possibilidade ausente do trabalho como experiencia expressiva, lúdica, criadora, que viabilizaria a composição do mundo, pelo trabalhador, na condição de criador, contraste com a realidade do trabalho forçado, sem investimento erótico, feito sem prazer, e que possibilita custear um pouco de vivencia prazeroza fora do trabalho. (Alves, 1986)

\section{E AGORA: PARA ONDE IR?}

na. A escola

enquanto tal para a

concretização

deste projeto de

viada, através da

priorização de

uma educação

A escola, como uma das princideformação e educação em tem um papel importante na

Depois de tantas reflexões acerca das relações entre trabalho e escola fica no ar a necessidade de buscarmos soluções e perspectivas para as mudanças profundas no conjunto de relações que envolvem estes dois universos. O propósito é de emancipação do ser humano através de uma nova relação com o trabalho que hoje, dentro da sociedade capitalista, apresenta-se como

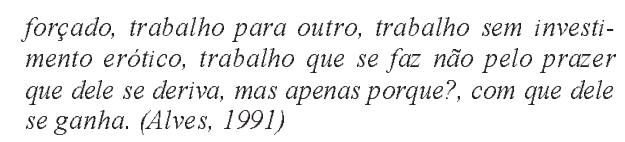

A escola, como uma das principais instituições de formação e educação em nossa sociedade, tem um papel importante na construção de uma nova lógica social, uma nova lógica de trabalho e uma nova lógica de relação humana. A escola enquanto tal poderia contribuir para a concretização deste projeto de virada, através da priorização de uma educação para e pelo lazer. Uma educação que não abrace mais o lazer condicionado ao mun- do do trabalho, ao consumo e à alienação, mas uma educação que tente caminhar para o fim da dicotomia entre trabalho e lazer, uma educação que valorize o humano e seus potenciais, o prazer, a emoção e o querer ser. Uma educação para e pelo lazer, que priorize a concepção de

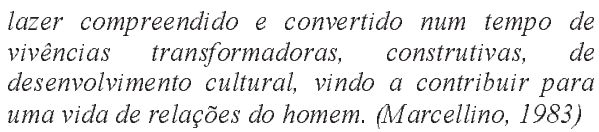

Para que isso ocorra, é preciso ampliar essas reflexões: Qual o tipo de instituição escolar desejamos construir? Será que instituição terá que vir sempre vinculada aos valores hegemônicos das práticas sociais do mundo do trabalho? Será que a instituição escolar estará sempre comprometida com a produção de conhecimentos legitimadores da razão instrumental? Será que a instituição escolar conseguirá construir espaços de vivência que não sejam apenas aqueles essenciais para a manutenção da lógica do trabalho alienado, isto é, a ordem fragmentária, racionalista e burocrática?

$\mathrm{Na}$ busca de tentar reverter tal ordem social seria preciso investir em reflexões e ações acreditando numa escola comprometida, não mais apenas com o trabalho mas com a emancipação do ser humano, uma escola que promova encontros interpessoais, uma escola construtora de cultura, uma escola que não reduza a educação ao ensino, uma escola que seja espaço fértil para o surgimento de um ser humano total, livre, crítico e criativo, onde a vivência lúdica possa se constituir numa possibilidade real de manifestação desta utopia.

E, para finalizar, usufruo do testemunho de ALVES:

A menos que você desista da lógica dominante da presente ordem das coisas e se torne criativo, não viverá para ver o futuro. Estará condenado à extinção. (Alves; apud Brunhs, 1992 p. 275)

\section{$\underline{\text { REFERÊNCIAS BIBLIOGRÁFICAS }}$}

ALVES, Rubem. A gestão do futuro. Campinas : Papirus, 1986.

BRACHT, Valter. Educação Física e aprendizagem social. Porto Alegre : Magister, 1992. 
BRUHUNS, Heloísa Turini. O culto do corpoprazer, o fenômeno lazer e o lúdico. Revista Brasileira de Ciências do Esporte, n.12, 1992, p.271-275.

FERNANDEZ, Enguita Mariano. A face oculta da escola: educação e trabalho no capitalismo. Porto Alegre : Artes Médicas, 1989.

HUIZINGA, Johan. Homo Ludens. 2 ed. São Paulo : Perspectiva, 1980.

MARCELLINO. Nelson Carvalho. Lazer $e$ Humanização. Campinas : Papirus, 1983. Lazer e Educação. Campinas : Papirus, 1987.

_. A sala de aula como espaço para o "jogo do saber". In: MORAIS, Regis de (Org). Sala de aula, que é esse? 4.ed. Campinas: Papirus, 1989 , p. $59-70$.

Pedagogia da Animação. Campinas: Papirus, 1990.
. Perspectivas para o lazer: mercadoria ou fi nal de utopia? In: MOREIRA, Wagner Wey. Educação Física e esportes - perspectivas para o século XXI. Campinas : Papirus, 1982. p. 161-179.

\section{UNITERMOS}

Escola - Trabalho - Lúdico - Educação Física-Lazer

*José Ângelo Gariglio é professor de Educação Física especialista em Educação Física escolar. Cursa, atualmente, o Mestrado em Educação da Faculdade de Educação da UFMG e leciona no Centro de Federal de Educação Tecnológica de Minas Gerais CEFETMG. 
